\title{
From Circuits to Chromatin: The Emerging Role of Epigenetics in Mental Health
}

\author{
${ }^{\circledR}$ Philipp Mews, ${ }^{1}{ }^{\circledR}$ Erin S. Calipari, ${ }^{2}{ }^{\circledR}$ Jeremy Day, ${ }^{3}{ }^{\circledR}$ Mary Kay Lobo, ${ }^{4}{ }^{\circledR}$ Timothy Bredy, ${ }^{5}$ and ${ }^{\circledR}$ Ted Abel ${ }^{6}$ \\ ${ }^{1}$ Friedman Brain Institute, Department of Neuroscience, Icahn School of Medicine at Mount Sinai, New York, New York 10129, ${ }^{2}$ Departments of \\ Pharmacology, Molecular Physiology and Biophysics, Psychiatry and Behavioral Sciences; Vanderbilt Center for Addiction Research; Vanderbilt \\ Brain Institute, Vanderbilt University, Nashville, Tennessee 37323, ${ }^{3}$ Department of Neurobiology, McKnight Brain Institute, University of Alabama \\ at Birmingham, Birmingham, Alabama 35294, ${ }^{4}$ Department of Anatomy and Neurobiology, University of Maryland School of Medicine, Baltimore, \\ Maryland 21201, ${ }^{5}$ Queensland Brain Institute, University of Queensland, Brisbane, 4072, Australia, and ${ }^{6}$ Department of Neuroscience and \\ Pharmacology, Iowa Neuroscience Institute, University of Iowa, Iowa City, Iowa 52242
}

A central goal of neuroscience research is to understand how experiences modify brain circuits to guide future adaptive behavior. In response to environmental stimuli, neural circuit activity engages gene regulatory mechanisms within each cell. This activity-dependent gene expression is governed, in part, by epigenetic processes that can produce persistent changes in both neural circuits and the epigenome itself. The complex interplay between circuit activity and neuronal gene regulation is vital to learning and memory, and, when disrupted, is linked to debilitating psychiatric conditions, such as substance use disorder. To develop clinical treatments, it is paramount to advance our understanding of how neural circuits and the epigenome cooperate to produce behavioral adaptation. Here, we discuss how new genetic tools, used to manipulate neural circuits and chromatin, have enabled the discovery of epigenetic processes that bring about long-lasting changes in behavior relevant to mental health and disease.

Key words: activity-dependent gene regulation; epigenome; lncRNA; memory engram; substance use disorder

\section{Introduction}

In 1942, Waddington coined the term "epigenetics" to explain phenotypic changes that occur with cellular differentiation throughout development (Waddington, 1942). As the brain and other tissues develop, cells progress through an elaborate process of fate specification involving accumulation of epigenetic signatures that direct gene expression through the molecular organization of chromatin, a compact composite of DNA and histone proteins (Rivera and Ren, 2013). All histones can undergo a multitude of post-translational modifications that dynamically regulate DNA accessibility and, ultimately, govern gene transcription. In their entirety, these epigenetic features have been denoted the epigenome, which operates at the intersection of genome, cellular activity, and the environment.

Over the past two decades, numerous chromatin-modifying and -remodeling enzymes have been discovered, many of which not only play roles during development but also have critical functions for epigenetic processes in differentiated

Received June 30, 2020; revised Dec. 19, 2020; accepted Dec. 22, 2020.

This work was supported by National Institute on Alcohol Abuse and Alcoholism K99AA027839 and Brain \& Behavior Research Foundation NARSAD Young Investigator Grant 28574 to P.M.; National Institute on Drug Abuse DA042111 and DA048931, as well as funding from the Brain and Behavior Research Foundation, the Whitehall Foundation, and the Edward Mallinckrodt Jr. Foundation to E.S.C.; National Institutes of Health DA039650, DA034681, and MH114990 to J.J.D.; National Institute on Drug Abuse R01DA038613, R01DA047843 to M.K.L.; and National Institute of Mental Health R01MH087463 to T.A.

P.M. is a co-founder of EpiVario, Inc. The remaining authors declare no competing financial interests.

Correspondence should be addressed to Philipp Mews at philipp.mews@mssm.edu.

https://doi.org/10.1523/JNEUROSCI.1649-20.2020

Copyright $\odot 2021$ the authors cells, including activity-dependent transcription in mature neurons (Levenson and Sweatt, 2006). Early evidence for a key role of chromatin regulation in neurons derived from studies focused on histone acetylation, often by manipulating the opposing activities of two families of epigenetic "writer" and "eraser" enzymes: the histone acetyltransferases (HATs) that acetylate histones and the histone deacetylases (HDACs) that remove acetyl groups. Histone acetylation was shown to relax the compact chromatin structure, thus rendering genes accessible to the transcriptional machinery and supporting gene activation (Shahbazian and Grunstein, 2007). In addition, acetylation and numerous other post-translational modifications of histones generate binding sites for "reader" proteins that coregulate gene expression; indeed, the majority of HAT and HDAC enzymes also contain bromodomains that allow their recruitment and binding to acetylated chromatin (Zaware and Zhou, 2019).

In the adult brain, histone acetylation was found to have broad effects on chromatin function and gene expression across different brain regions and neuronal subtypes, and is most famously implicated in processes of learning and memory (Gräff and Tsai, 2013; Peixoto and Abel, 2013; Mews et al., 2017, 2019). In recent years, an avalanche of epigenetic mechanisms has been discovered that likewise influence gene expression involved in memory formation. These include not only numerous other histone marks, such as methylation, phosphorylation, ubiquitylation, and sumoylation, but also histone protein variants, chromatin looping, long noncoding RNAs (lncRNAs), DNA methylation, and DNA damage (Wood et al., 2006a; Zovkic et al., 2014; Madabhushi et al., 2015). The ever-expanding 


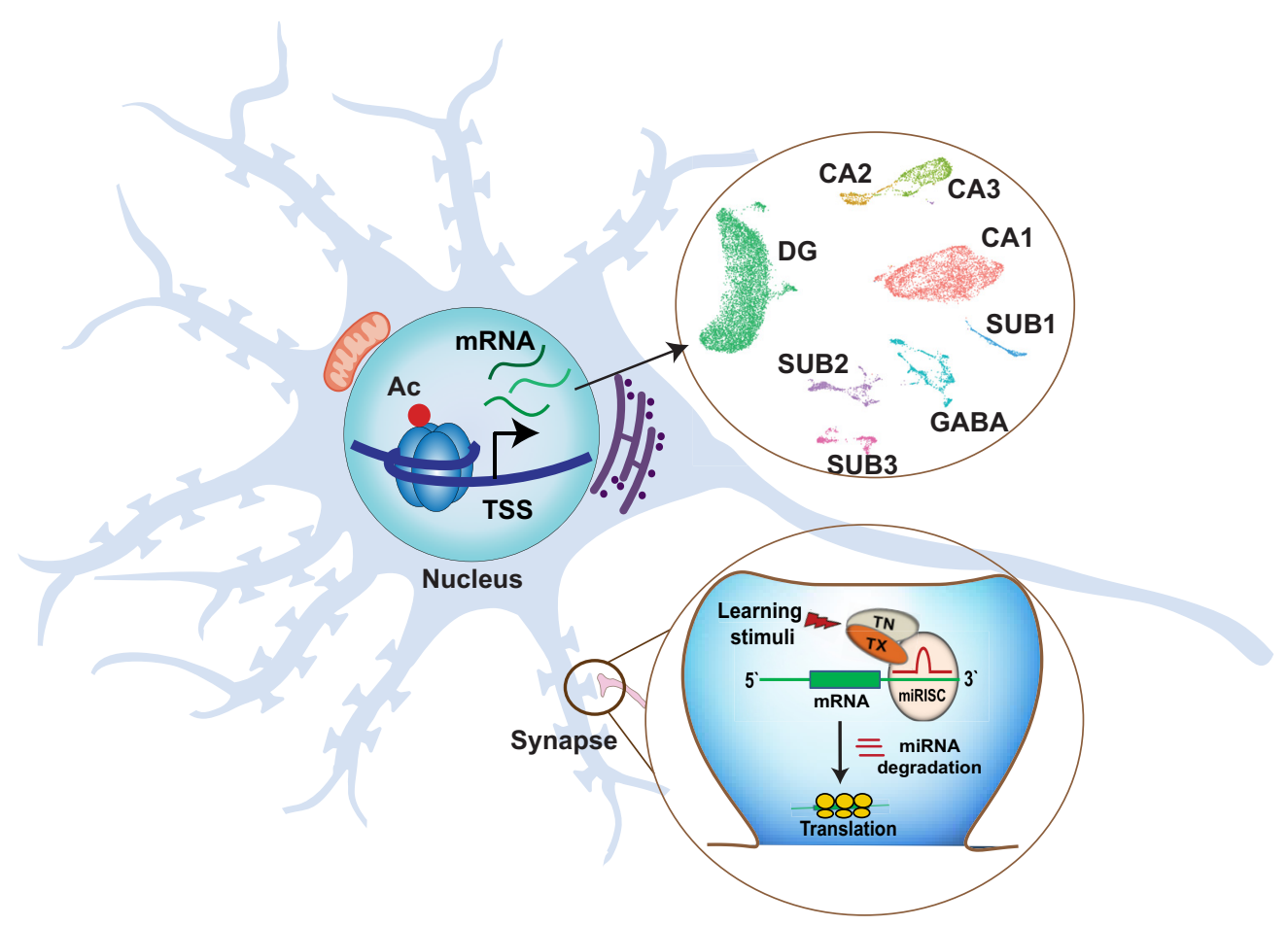

Figure 1. Epigenetic mechanisms regulate cell type-specific gene expression involved in memory storage. Histone modifications, such as acetylation and methylation, regulate gene expression in response to experience (e.g., Mews et al., 2017). Newly developed sequencing technology enables the study of gene expression at the single-cell level and allows insight into the enormous heterogeneity of gene activity profiles within defined neuronal populations. For example, snRNA-seq performed on hippocampal brain tissue enables cluster analysis that groups individual single-cell transcriptomes by subregion and cell type. This approach can identify sets of marker genes whose expression distinguishes any such cluster. Shown is a projection of individual cells following global dimensionality reduction that congregate into clusters representing the hippocampal subregions CA1, CA2, and CA3, the subiculum (SUB1-SUB3), the dentate gyrus $(D G)$, and GABAergic interneurons (GABA). Epigenetic mechanisms also act at the synapse, where microRNAs and IncRNAs regulate the localized translation and stability of mRNA transcripts that encode proteins central to synaptic plasticity (Park et al., 2017; Madugalle et al., 2020).

complexity of chromatin dynamics is highlighted by new reports revealing that histones can be directly targeted and modified by serotonin and dopamine, two neurotransmitters that regulate neuron activity during memory storage and retrieval (Farrelly et al., 2019; Lepack et al., 2020).

Both transient and long-lasting changes in neuronal chromatin structure are emerging with essential roles for memory and the expression of complex behaviors; and it is evident that dysregulation in these processes is central to vulnerability, manifestation, and trajectory of mental health disorders (Bastle and Maze, 2019). One such example is substance use disorder, where chromatin-based processes have been linked to persistent changes in neural circuit activity and behavior (Mews and Calipari, 2017; Nestler and Lüscher, 2019). However, although years of research have shown that epigenetic mechanisms are critical to learning and behavioral control, the fundamental question of how epigenetic processes within neural circuits help transform experiences into long-term memory remains to be fully understood.

\section{Neuronal activity shapes the epigenome}

The epigenome operates at the interface of the environment and the genome, and is readily manipulated by neuronal circuit activity to coordinate circuit-specific gene expression that supports neural plasticity (Levenson and Sweatt, 2005; Campbell and Wood, 2019; Nestler and Lüscher, 2019). When organisms navigate an environment, various stimuli activate neural circuits that are involved in processing remarkably complex sensory information, which can differ in valence, novelty, salience, and motivational value. Any given stimulus may activate only a small coordinated group of neurons, referred to as ensemble, leading to plasticity within neural circuits that determines how cells are recruited in the future (Poo et al., 2016). To support such stimulus-induced plasticity and to precisely guide adaptive behavior, brain circuits are structurally reorganized involving activity-dependent gene expression (Alberini and Kandel, 2014; Rotem et al., 2015; Fernandez-Albert et al., 2019; Josselyn and Tonegawa, 2020; Marco et al., 2020).

Upon neuronal stimulation, calcium influx and G proteincoupled receptors activate intracellular signaling cascades, including the PKA and MAPK/ERK pathways, that transmit information about circuit activity into the cell nucleus, where epigenetic processes drive and maintain changes in gene transcription (Gräff and Tsai, 2013) (Fig. 1). To make genes involved in neural plasticity accessible to RNA polymerase, the compact chromatin structure must be temporarily "opened." This process involves the recruitment of chromatin-modifying enzymes to immediate-early genes (e.g., Fos, FosB, and Junb), which become rapidly induced and subsequently regulate numerous other genes that encode membrane receptors and neuronal signaling proteins, which, in turn, modify the excitability and connectivity of neural circuits (Mews and Calipari, 2017). Notably, while it is well established that transient changes in chromatin mediate acute transcription in response to neuronal activity, evidence has been accumulating that certain epigenetic marks have long-lasting effects on gene expression that outlive the initial transient signal of neural stimulation (Robison and Nestler, 2011; Fischer, 2014). In this view, epigenetic signatures emerge as vital molecular components of the memory engram. They are predicted to maintain changes in neural circuits that lastingly adapt behavior to the environment. 


\section{Epigenetic regulation in learning and memory}

Neuronal activity results in dynamic gene expression that supports synaptic plasticity required for long-term memory and future behavioral responses (Zovkic, 2020). Because epigenetic mechanisms are central to this process, the question of how genome-wide changes in neuronal chromatin may dictate circuitand engram-specific plasticity has become a significant focus of ongoing research (Nestler and Lüscher, 2019). Advancing our understanding of such chromatin-based mechanisms in memory is anticipated to not only have wide-ranging impact in molecular neuroscience but also across clinical research on memory-related disorders.

As outlined above, at the cellular level, the initial encoding of memory involves activity-dependent gene expression that necessitates dynamic chromatin changes. As early as 1979, it was found that brain chromatin becomes acetylated when rats undergo memory consolidation (Schmitt and Matthies, 1979). However, the mechanistic insight from such early observations was limited because the genomic regions that underwent histone acetylation could not be identified. More recent studies using chromatin immunoprecipitation revealed that memory-related histone acetylation is specific to the regulatory enhancer and promoter regions of individual genes, including immediate-early genes that have long been implicated in learning and memory (e.g., Erg1, Fos, and Bdnf). All these genes become quickly upregulated at the time of their transiently increased acetylation state (Korzus et al., 2004; Peleg et al., 2010; Oliveira et al., 2011; Bannerman et al., 2014; Mews et al., 2017).

Further, early experiments showed that memory storage can be blocked by pharmacological inhibition of protein synthesis after learning, and that this sensitive period coincides with the transient phosphorylation of CREB (Bourtchouladze et al., 1998). Kinases activate this transcription factor on neuronal stimulation and release of cAMP or $\mathrm{Ca}^{2+}$. Phosphorylated CREB protein binds to cAMP response elements in the DNA and recruits a key HAT enzyme involved in memory, the CREBbinding protein $(\mathrm{CBP} / \mathrm{KAT} 3 \mathrm{~A})$, to increase acetylation and expression of its target genes (Gerritsen et al., 1997; Gräff and Tsai, 2013; Bridi et al., 2017). The functional importance of histone acetylation for memory formation was subsequently demonstrated in genetic mouse models in which the activity of CBP was reduced (Alarcón et al., 2004; Wood et al., 2005, 2006b; Barrett et al., 2011; Oliveira et al., 2011). Correspondingly, memory consolidation could be enhanced when the catalytic activity of HDACs was blocked pharmacologically, resulting in increased histone acetylation (Levenson et al., 2004; Fischer et al., 2007, 2010; Vecsey et al., 2007; Stefanko et al., 2009; Haettig et al., 2011).

Interestingly, HDAC inhibitor (HDACi) administration alone generally has little effect on gene expression and produces few side effects across different brain areas and tissues (J. Chandra et al., 2011; Gräff et al., 2014). To explain this phenomenon, the concept of cognitive epigenetic "priming" was put forward. Accordingly, HDACi treatment enhances histone acetylation to prime genes for rapid activation. It thus amplifies the induction of transcriptional programs downstream of learning-related circuit activity and neuronal signaling, thereby boosting memory formation (Gräff and Tsai, 2013). Follow-up studies have corroborated the link between histone acetylation, stimulus-dependent gene expression, and different phases of memory, thus supporting a mechanism whereby HDACi-induced epigenetic priming may ameliorate memory (Burns and Gräff, 2020). In addition to histone acetylation, many other neuro-epigenetic processes have emerged with critical roles for activity-dependent transcription and synaptic plasticity, highlighting the importance of epigenome regulation in information storage and normal brain function (for review, see Campbell and Wood, 2019). However, despite this scientific progress, the chromatin-based mechanisms that precisely govern gene expression in neuronal ensembles for memory storage, maintenance, and retrieval remain not fully understood.

A valuable approach that emerged in recent years to investigate epigenetic processes within engram ensembles relies on the activity-dependent expression of reporter proteins. By taking advantage of this tactic to label engram cells, a new study determined that ensembles are indeed marked at the epigenetic level, as memory encoding was found to have lasting effects on chromatin accessibility and promoter-enhancer interactions (Marco et al., 2020). Interestingly, the encoding of contextual fear memory was characterized by widespread increases in enhancer accessibility without the expected transcriptional changes, indicating a potential priming mechanism. Indeed, reactivation of engram neurons on memory recall revealed that a large subset of these "primed" enhancers forms de novo promoter-enhancer interactions, associated with robust gene expression that regulates localized protein synthesis and synaptic morphogenesis (Marco et al., 2020). Similarly, a different study recently demonstrated that stimulation of excitatory hippocampal neurons induces gene loops and lastingly strengthens promoter-enhancer interactions that become an enduring feature of epigenomic signatures linked to neuronal activation (Fernandez-Albert et al., 2019). Together, these data suggest that one of the ways neurons are incorporated into ensembles involves epigenetic plasticity, providing experimental evidence for epigenetic priming in engram neurons (Marco et al., 2020).

Notably, the transcriptional program induced on reactivation of engram neurons includes the expression of proteins involved in mRNA transport and synapse-localized translation (Marco et al., 2020). Studies have previously shown that thousands of plasticity-related transcripts localize to the synaptic neuropil (Cajigas et al., 2012), far outside the cell nucleus. Activity-dependent translation of these protein-coding transcripts plays a crucial role in synaptic plasticity, and miRNA-dependent mechanisms are emerging with essential functions in controlling this process (Fig. 1). Synapse-localized mRNA transcripts were found to be translationally repressed by microRNAs, reminiscent of a translational regulatory mechanism that may bring about synapsespecific modifications in an activity-dependent manner (Chern et al., 2019). Indeed, research led by T.A.'s group at the University of Iowa revealed that microRNAs could be degraded by the translin/trax RNase complex on neuronal stimulation, which reverses translational silencing and therefore disinhibits the synthesis of synaptic proteins needed for long-term memory consolidation (Fu et al., 2016; Park et al., 2017; Baraban et al., 2018). Given the importance of such local processes for synaptic plasticity and brain function (Martin et al., 2000; Sutton and Schuman, 2006), miRNA-dependent regulation of local translation appears to be a neuro-epigenetic strategy that is critical to mental health and disease (Hu and Li, 2017).

\section{Drugs of abuse co-opt activity-dependent transcription to influence neuronal function}

Together, the discoveries mentioned above offer significant insight into epigenetic regulation of activity-dependent transcription in learning and memory. This process is vital to basic behavioral control and can be dysregulated by a wide range of 


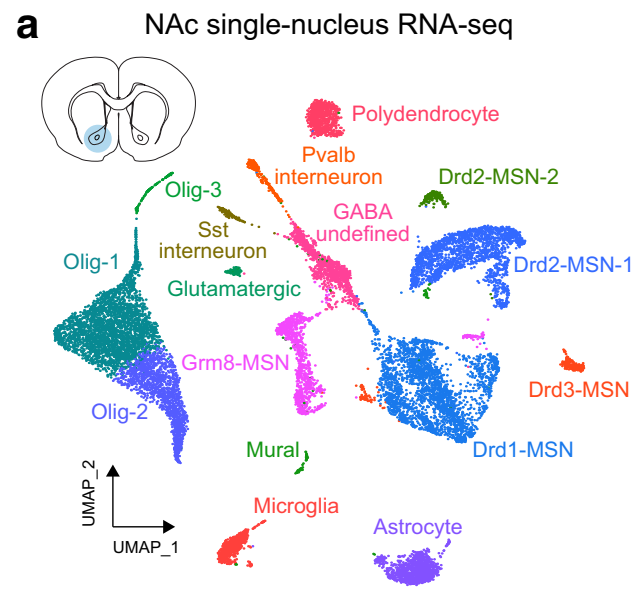

\section{C}

\section{Fosb}
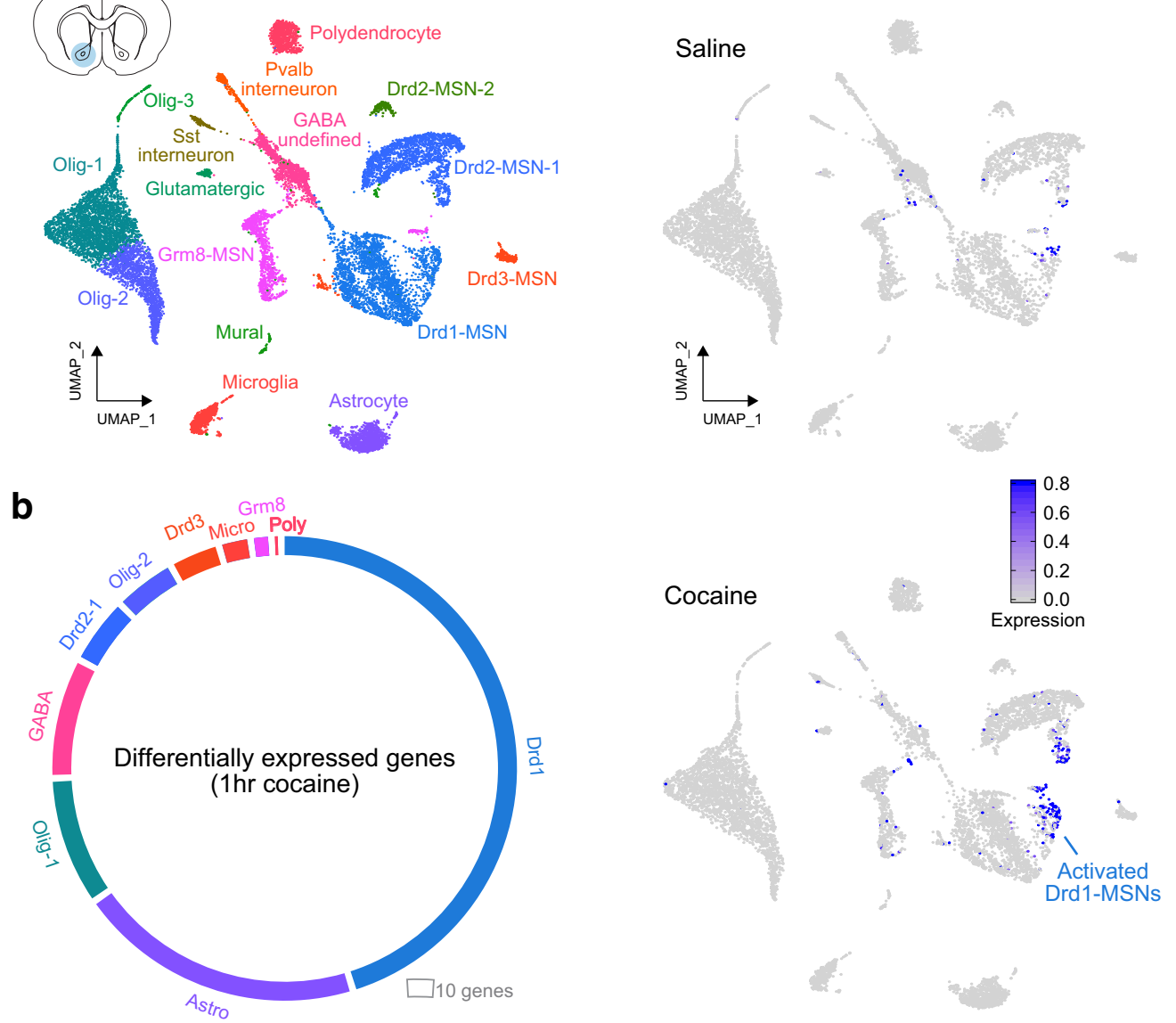

Figure 2. Single-nucleus RNA-seq reveals cell-specific transcriptional response to cocaine. $\boldsymbol{a}$, Global dimensionality reduction clustering (UMAP) of 15,631 individual NAc nuclei identifies 16 transcriptionally distinct cell classes of the rat NAc, including MSNs expressing Drd1 and Drd2 mRNA. $\boldsymbol{b}$, Circos plot of differentially expressed genes $1 \mathrm{~h}$ after cocaine administration, analyzed within each cell type. Cocaine differentially expressed genes are most abundant in Drd1-MSNs, followed by astrocytes. c, UMAP plot from $\boldsymbol{a}$ in gray with the representative expression of Fosb, a cocaine-responsive immediate-early gene. Fosb mRNA expression is increased in a small fraction of "activated" Drd1-MSNs. Data from Savell et al. (2020).

psychiatric disease states. Preclinical research has revealed that alterations in chromatin and gene expression underlie various memory-related brain disorders, with substance use disorder (the primary focus of this review) being widely studied. In substance use disorder, drugs of abuse hijack processes in the brain that control reward learning to drive aberrant behavioral responses that develop with repeated exposure to these drugs (Volkow and Morales, 2015). The neural source of these behavioral changes has been linked to dysfunction in neural circuits across the brain (Koob and Volkow, 2016); however, pinpointing the molecular and epigenetic drivers that allow these circuit changes to persist throughout prolonged periods of withdrawal has been difficult because of the complicated technical nature of these studies.

Despite their very different chemical structures and initial protein targets, drugs of abuse ultimately converge by producing long-lasting changes in gene regulation in a central brain region of reward, the nucleus accumbens (NAc) (Robison and Nestler, 2011; Mews and Calipari, 2017). In the NAc, drugs of abuse elevate dopamine levels and consequently alter transcriptional programs that are believed to promote long-lasting synaptic and behavioral adaptations (Day et al., 2007). The NAc is primarily composed of two distinct types of medium spiny neurons (MSNs), the D1 and D2 dopamine receptor-expressing subtypes, which exhibit dramatic differences in activity and effects on drug reward (Surmeier et al., 2007; Lobo and Nestler, 2011). However, even with well-studied drugs, such as cocaine, drug-induced transcriptional responses in the NAc remain poorly understood because of cellular heterogeneity and complex drug actions via multiple neurotransmitter systems. To overcome these challenges, high-throughput single-nucleus RNA-sequencing (snRNA-seq) is being used in newer studies to transcriptionally define drug-induced gene expression signatures with single-cell resolution (Savell et al., 2020) (Fig. 2).

To create a comprehensive molecular atlas of cellular subtypes in the NAc, a recent study from J.D.'s group at the University of Alabama at Birmingham used snRNA-seq and defined cell type-specific responses to acute drug experience in a rat model system of cocaine experience (Savell et al., 2020). This transcriptional map enabled the identification of specific neuronal subpopulations that are activated by cocaine and allowed characterization of an immediate-early gene expression program that is upregulated in subclusters of D1-MSNs following cocaine experience (Fig. 2). This set of dopamine-responsive genes was enriched for CREB-binding motifs, indicating that classical CREB-mediated induction of immediate-early genes drives the dopamine-induced gene expression program. Computational analyses further revealed that multiple genes exhibited high predictive power in marking the cocaine-activated subcluster, indicating that key neuronal genes (e.g., the postsynaptic scaffold 
protein gene Homer 1 and the neurotrophin receptor Ntrk2) may facilitate the recruitment of individual cells into an ensemble encoding drug-related memory (Fig. 2).

To further characterize the neuronal response to this dopamine-mediated gene expression, a large-scale CRISPR/dCas9based activation strategy was engineered that re-creates the induction of this gene expression program. By conjugating domains of known enzymatic transcriptional activators (e.g., VP64, to CRISPR/dCas9 fusion proteins that are targeted to specific gene-regulatory loci), genes that are central to dopaminemediated gene expression can be directly activated (Savell et al., 2019). The multiplexed induction of the core immediate-early gene program (Dopaplex) initiated a secondary synapse-centric transcriptional profile, and not only altered striatal physiology in vitro, but also enhanced cocaine sensitization in vivo (Savell et al., 2020). These findings illustrate how recent advances in genetic tools and sequencing technology enable the characterization of activity-related transcriptional responses, both across the genome and with cellular precision. Notably, this study also demonstrates that drug-responsive gene programs are sufficient to initiate physiological and behavioral adaptations to drugs of abuse. However, there are still gaps in knowledge regarding the cellular and molecular mechanisms that underlie the disruptions in neural plasticity and motivation caused by repeated exposure to drugs of abuse.

\section{Dopamine-regulated gene programs and the role of transcription factors in motivation}

Early studies investigating transcriptional changes in the NAc and other brain regions involved in reward discovered that the transcription factor $\Delta$ FosB becomes upregulated with chronic drug exposure (Nestler et al., 2001). This protein is a unique member of the AP1 family of transcription factors, as its exceptional stability causes it to accumulate to high levels with repeated drug exposure. This uncommon stability of $\Delta$ FosB presents an attractive candidate mechanism through which transient gene expression induced by drugs of abuse can produce persistent changes in gene regulation.

More recent evidence from M.K.L.'s group at the University of Maryland indicates that another transcription factor, early growth response 3 (Egr3), also plays a key role in the response to drug-related dopamine signaling and the transition to substance use disorder (R. Chandra et al., 2015). Their research showed that repeated exposure to cocaine has opposite effects on Egr3 expression in D1 and D2 subtypes of NAc MSNs (R. Chandra et al., 2015). Further, when Egr3 expression was genetically disrupted in either MSN subtype in mice, both cocaine-seeking and sensitization behaviors were blunted. Examination of candidate target genes with Egr3 binding sites revealed that many chromatin-modifying enzymes are putative transcriptional targets of Egr3, including histone lysine demethylases (HDMs). Moreover, Egr3 was found to regulate two key mitochondria-related molecules that support synaptic plasticity in the NAc, namely, Drp1, which mediates fission, and PGC-1a, a transcriptional activator (Z. Li et al., 2004; X. Li et al., 2010; Cheng et al., 2012; R. Chandra et al., 2017b; Divakaruni et al., 2018; Cole et al., 2020). Circuit-specific reduction of Drp1 expression in D1-MSNs resulted in markedly lowered drug-seeking behavior after cocaine self-administration. Correspondingly, disruption of mitochondrial fission was found to blunt cocaine-induced synaptic plasticity in D1-MSNs (R. Chandra et al., 2017a). Furthermore, enhancement of PGC- $1 \alpha$ in either D1-MSNs or D2-MSNs bidirectionally altered cocaine-induced behaviors ( $\mathrm{R}$. Chandra et al., 2017b). Consistent with its role in regulating these transcriptional targets, genetic disruption of Egr3 in D1-MSNs was shown to prevent cocaine-induced mitochondrial fission in these neurons (Cole et al., 2020).

The link between Egr3, histone-modifying enzymes, and mitochondrial molecules suggests that cocaine induces circuit-specific epigenetic adaptations in the striatum, linked to disturbed neuron plasticity and disrupted motivation ( $\mathrm{R}$. Chandra et al., 2017a; Engeln et al., 2020). It is also plausible that Egr3 controls its own transcription by influencing the expression and abundance of gene-regulatory HDMs. Mechanistic insight into these questions may be gained by using newly developed genetic tools that use CRISPR fusion proteins, discussed above, to engineer the epigenome at these central cocaine-regulated genes. These cutting-edge tools can be used to manipulate histone methylation at the Egr3 promoter and at mitochondrial protein genes, to determine whether circuit-specific epigenetic regulation of these targets influences cocaine-induced transcription and drugrelated behaviors.

\section{Epigenetic priming supports persistent changes in activity- induced transcription}

An ongoing focus of research into the molecular pathology of substance use disorder is exploring mechanisms that preserve altered patterns of gene regulation across the brain's reward circuitry. Long after the initial effects of chronic drug exposure have faded, changes in the transcriptional states of drug-responsive neurons can persist, even throughout prolonged withdrawal (Feng et al., 2014; Maze et al., 2014; Walker et al., 2018). Permanent modifications in chromatin structure are hypothesized to cause these lasting changes in gene transcription. Akin to epigenetic priming mechanisms in learning and memory that mediate enhanced transcriptional responses to neuronal reactivation on memory recall (Gräff and Tsai, 2013; Marco et al., 2020), changes in chromatin may influence reward-related gene expression on a timescale that extends far beyond the initial drug stimulus. Such lasting aberrations in the epigenome may also contribute to maladaptive behaviors in substance use disorder. Indeed, epigenetic remodeling has emerged as a potent regulator of drug-induced plasticity and is implicated in addiction to stimulants, opiates, ethanol, and nicotine (Walker et al., 2015). However, the relationship between drug-induced epigenetic modifications and aberrant gene regulation that contributes to relapse remains unclear.

Recent investigations into relapse-associated gene expression revealed that, following cocaine self-administration, large sets of genes are transcriptionally primed within the NAc and other reward-related brain regions (Walker et al., 2018). These primed genes remain highly responsive to drug-related circuit activity even after prolonged withdrawal, and among them are synaptic proteins that contribute to drug-related adaptations on the circuit level, such as AMPAR and NMDAR subunits (Pierce et al., 1996; Reid and Berger, 1996; Baker et al., 2003; Kourrich et al., 2007; Kau et al., 2008). Notably, cocaine-related increases in striatal AMPAR expression have been linked to the insertion of AMPARs that lack the GluR2 subunit, which renders them calcium-permeable (Conrad et al., 2008). This shift in synaptic receptor composition likely augments calcium-mediated signaling cascades that potentially reinforce cocaine-induced chromatin changes with potent effects on drug craving.

Bioinformatic analysis predicts well-known transcription factors as upstream regulators of relapse-related gene expression: among the highest-ranked factors are, again, CREB and AP1, 
thus validating prior work on the initial actions of drugs of abuse discussed earlier. Remarkably, within a given brain region, different sets of transcripts are regulated by each identified transcription factor before and after chronic drug exposure (Walker et al., 2018). These findings indicate an essential layer of regulation, in addition to altered signaling because of structural changes at the synapse: the epigenetic landscape may ultimately determine the inducibility of discrete gene programs that characterize substance use disorder. A fundamental challenge is to determine the drug-related changes in chromatin for each neuronal subtype. As the functionally distinct D1 and D2 MSN subtypes exhibit dramatic differences in activity and effects on drug reward, ongoing work aims to investigate the discrete chromatin alterations in these separate striatal circuits.

One recent approach to detect "open" chromatin regions that are indicative of active gene transcription or priming is the use of assay for transposase-accessible chromatin with sequencing (Buenrostro et al., 2015). Using fluorescence-activated nuclei sorting coupled to assay for transposase-accessible chromatin with sequencing, chromatin accessibility has been surveyed genome-wide in purified populations of D1 and D2 MSNs to assess changes after acute or chronic cocaine exposure, and after prolonged withdrawal (Mews et al., 2018). These preliminary data indicate that chromatin "opening" occurs selectively in D1 MSNs on acute exposure to cocaine. This cocaine-related accessibility is also linked to the induction of neuronal gene programs outlined above (P.M. and Eric J. Nestler, unpublished observations). Notably, although preliminary, these neuron-subtype-specific data indicate that D1 chromatin accessibility persists even after prolonged withdrawal from chronic cocaine exposure. It suggests that epigenome remodeling in D1 MSNs may mediate the enduring effects of drug exposure on striatal gene regulation. We posit that chronic cocaine exposure alters the chromatin landscape in D1 MSNs in a way that primes drug-related gene expression programs, which ultimately support the enduring changes in synaptic connectivity and behavior (Mews et al., 2018).

\section{Circuit-specific adaptations in the striatal epigenome of males and females control the transition to addiction}

Whereas a large amount of work has focused on the transcriptional and epigenetic processes that are dysregulated to drive substance use disorder, one often overlooked factor is the contribution of biological sex to these processes (Zachry et al., 2019). Notably, the sex-specific effects of cocaine in the NAc have been identified as key factors that enhance motivation for cocaine in females. Thus, studies that define the interplay between neuronal activation and long-term epigenetic remodeling are critical to understanding and treating addiction disorders in both sexes (Johnson et al., 2019). To this end, an ongoing study is combining cocaine self-administration in male and female C57BL6/J mice with transcriptional and proteomic profiling to identify unique molecular signatures that underlie druginduced plasticity.

As many have reported previously, in rodents, females are more motivated to self-administer both natural reinforcers and cocaine, suggesting that females may be more vulnerable to the reinforcing properties of drugs, especially stimulants (Becker et al., 2017). Further, differences in motivation for natural reinforcers suggest key differences between males and females at baseline that could interact with drug-induced plasticity to alter the trajectory of cocaine-induced changes within the brain (Kutlu et al., 2020). To investigate this sexual dichotomy, E.S.C. and her group at Vanderbilt University recently assessed cocaine-induced sex-specific alterations in the proteomic and transcriptional landscape that occur independently of differences in drug intake. Notably, even in situations where drug consumption was matched between the sexes, robust differences in cocaine-induced proteomic regulation emerged. These studies found that cocaine-induced a sex-specific proteomic signature that was nearly nonoverlapping between males and females.

Intriguingly, analysis of upstream regulators identified multiple activity-dependent HATs that are regulated by cocaine in both males and females. As discussed above, dynamic histone acetylation is an essential mediator of transient gene expression directed by transcription factors in response to neuronal activation. Indeed, cocaine self-administration was associated with increased acetylation of the same histone lysine residues in both sexes, while the specific transcriptional outputs were distinct. Together, these data suggest that cocaine engages shared intracellular signaling cascades and HATs that, however, mediate sex-specific gene acetylation and differential transcription. Conceivably, males and females are characterized by distinct circuit-specific epigenetic signatures, which collectively determine what genes may respond to intracellular signaling by cocaine, therefore priming differential downstream transcriptional programs and sex-specific protein expression. In this context, it will be of interest to investigate the sex-specific role of other chromatin modifications linked to activity-dependent gene regulation, such as relatively stable methylation of histones and the DNA itself. Whereas the transcriptional response to cocaine is sex-specific, the indistinguishable behavior at these time points suggests that mechanisms driving cocaine-induced plasticity and behavioral control occur through different molecular effectors. These data highlight that understanding the unique sex-specific mechanisms that drive cocaine use disorder will be essential to developing widely efficacious treatments. 


\section{Emerging players in the epigenetic regulation of memory- related gene expression}

We are still at the frontier of understanding how epigenetic regulation governs brain function in mental health and disease. While histone modifiers, such as histone methyltransferases (HMTs), HDMs, HATs, and HDACs, have been a focus of epigenetic regulation, there are other epigenetic factors that continue to emerge, such as the generation of metabolites used in histone modification or regulation by different classes of noncoding RNAs that have potent effects on activity-dependent gene expression, learning and memory, and disease states.

\section{Chromatin as a hub connecting metabolism to epigenetic regula- tion in the brain}

In recent years, chromatin-bound metabolic enzymes have emerged as important players in epigenetic regulation (Boon et al., 2020), leading to a fundamental shift in models of transcriptional regulation and implicating epigenetic-metabolic processes in brain function and behavior. Provocative findings of metabolic enzymes regulating histone acetylation indicate that the production of metabolic cofactors directly on chromatin may allow the plasticity, dynamism, and speed required for hippocampal learning and memory (Mews et al., 2017; Sharma and Rando, 2017). Several acetyl-CoA-generating enzymes reside directly inside the cell nucleus and were found to drive gene expression programs by fueling local histone acetylation with this key metabolite (Wellen et al., 2009; Comerford et al., 2014; Pietrocola et al., 2015; Mews et al., 2017). In the hippocampus, the metabolic enzyme acetyl-CoA synthetase 2 (ACSS2) directly binds to chromatin at key neuronal genes and interacts with CBP to promote histone acetylation locally, thereby supporting the transcription of plasticity-related genes during memory encoding (Mews et al., 2017) (Fig. 3).

New findings indicate that histone acetylation in the brain may also be under the direct influence of extracellular levels of acetate (Soliman and Rosenberger, 2011; Mews et al., 2017, 2019). Notably, a major source of acetate is breakdown of alcohol in the liver, leading to rapidly increasing blood acetate (Sarkola et al., 2002; Pardo et al., 2013), the critical substrate used by the metabolic enzyme ACSS2 to produce acetyl-CoA in neurons. A recent report by Mews et al. (2019) used mass spectrometry to track the fate of isotopically labeled alcohol, which revealed that alcohol-derived acetate is rapidly incorporated into brain histones. The direct contribution of alcohol to histone acetylation was found to rely on the catalytic activity of neuronal ACSS2, and behavioral experiments confirmed that this metabolic-epigenetic process plays an important role in alcohol-related learning by coordinating alcohol-induced gene expression in the hippocampus (Mews et al., 2019) (Fig. 3).

The link between alcohol metabolism and histone acetylation in the brain suggests that other external sources of acetate (primarily sour foods and the gut microbiome) may similarly affect histone acetylation to modulate memory (Cryan and Dinan, 2012; Mao et al., 2020; Moffett et al., 2020). Indeed, recent evidence has demonstrated that the gut microbiome has marked effects on neuronal function and behavior (Moffett et al., 2020). Gut-derived short-chain fatty acids (SCFAs) are well documented to inhibit HDAC activity and alter transcription factor activity (Davie, 2003; Shah et al., 2006). New evidence from mouse models of morphine disorder further showed that replacement of SCFA metabolites reverses the behavioral and transcriptional effects of microbiome depletion (Hofford et al., 2020). Together, these new studies add important mechanistic insight into the role of gut-brain signaling for molecular and behavioral changes in mental health and disease, especially substance use disorders.

\section{IncRNA in the epigenetic regulation of memory-related gene expression}

Another nontraditional but potent class of epigenetic regulators is lncRNAs, which have recently gained widespread attention because of their multidimensional capacity as decoys for transcription factors, modular scaffolds, and guides to direct chromatin modifiers within the nucleus (Mercer and Mattick, 2013). lncRNAs, defined as any RNA longer than 200 bases that do not code for protein, represent the most abundant family of noncoding RNA in the brain. IncRNAs are expressed in a highly celltype- and spatiotemporally restricted manner (Mercer et al., 2008), which uniquely positions them to mediate rapid adaptive neuronal responses. Not surprisingly, lncRNA activity has been implicated in the regulation of gene expression underlying depression, impulsivity, and anxiety. For example, the lncRNA Gm12371 was recently shown to influence hippocampal dendritic morphology and synaptic plasticity (Raveendra et al., 2018).

Research on how lncRNA activity regulates fear extinction by T.B.'s group at the University of Queensland has yielded new insight into this process. In fear conditioning, animals learn about associations between predictive cues and aversive outcomes, such as a tone predicting foot shock, which drives the conditioned behavioral response (freezing) to the previously neutral cue. In fear extinction, animals experience the conditioned cue in the absence of the aversive outcome. Thus, extinction is a learning process where animals learn that the previous cue-outcome relationship no longer exists. Similar associative learning processes are critical mediators of substance use disorder, where animals learn to associate environmental cues with drug effects. These associations, and an impaired ability to update them when they no longer exist, are critical mediators of relapse. Thus, defining the neural mechanisms mediating extinction learning has been a major focus of neuroscience research.

Using a targeted RNA sequencing approach, T.B.'s group discovered a significant number of novel experience-dependent lncRNAs, including a unique population with features of functional enhancer RNAs, as indicated by increased chromatin accessibility and marked by acetylation of histone H3 lysine 27. More than $100 \operatorname{lncRNAs}$ derived from putative enhancer elements were induced by fear extinction learning, including a novel activity-induced lncRNA that they have named ADRAM (activity-dependent lncRNA associated with memory), whose expression is necessary for fear extinction. Notably, ADRAM does not regulate proximal gene expression by forming a DNA: RNA hybrid, referred to as R-loop, or by long-distance DNADNA interactions, as previously observed for enhancer RNAs, but instead serves as a guide. ADRAM interacts with the brainenriched chaperone protein 14-3-3 to recruit the histone-modifying enzyme CBP to the promoter of the memory-associated immediate-early gene NR4A2, resulting in enhanced expression of NR4A2 (T.B., unpublished observation). Notably, knockdown of ADRAM disrupts this interaction and blocks the learning-induced expression of NR4A2, thus impairing fear extinction memory. Together, these findings broaden our understanding of the scope of experience-dependent lncRNA activity in the adult brain and highlight enhancer-derived lncRNAs, including ADRAM, as key drivers of the epigenetic regulation of gene expression in memory processes. 
In conclusion, looking forward, a deep mechanistic understanding of how neural circuit activity and the epigenome interact to integrate a plethora of stimuli and shape behavior will pave the way for new therapeutic interventions in neuropsychiatric disease. One major challenge has been to functionally link epigenetic changes (at specific loci, in specific cells) to behavioral outcomes. Innovative and evolving CRISPR-based technology, as outlined in this review, allows targeted modification of key generegulatory chromatin loci to assay effects on behavior in preclinical animal models and will help advance mechanistic studies of reward processing and higher brain function ( $\mathrm{Xu}$ and Heller, 2019; Yim et al., 2020). Such investigation into the complexity of epigenetic mechanisms at play across the distinct neuronal cell types and circuits of the adult brain promises significant insight about new targets to combat neuropsychiatric disorders, such as substance use disorder.

\section{References}

Alarcón JM, Malleret G, Touzani K, Vronskaya S, Ishii S, Kandel ER, Barco A (2004) Chromatin acetylation, memory, and LTP are impaired in $\mathrm{CBP}^{+/-}$mice: a model for the cognitive deficit in Rubinstein-Taybi syndrome and its amelioration. Neuron 42:947-959.

Alberini CM, Kandel ER (2014) The regulation of transcription in memory consolidation. Cold Spring Harb Perspect Biol 7:a021741.

Baker DA, McFarland K, Lake RW, Shen H, Tang XC, Toda S, Kalivas PW (2003) Neuroadaptations in cystine-glutamate exchange underlie cocaine relapse. Nat Neurosci 6:743-749.

Bannerman DM, Sprengel R, Sanderson DJ, McHugh SB, Rawlins JN, Monyer H, Seeburg PH (2014) Hippocampal synaptic plasticity, spatial memory and anxiety. Nat Rev Neurosci 15:181-192.

Baraban JM, Shah A, Fu X (2018) Multiple pathways mediate microRNA degradation: focus on the translin/trax RNase complex. Adv Pharmacol 82:1-20.

Barrett RM, Malvaez M, Kramar E, Matheos DP, Arrizon A, Cabrera SM, Lynch G, Greene RW, Wood MA (2011) Hippocampal focal knockout of CBP affects specific histone modifications, long-term potentiation, and long-term memory. Neuropsychopharmacology 36:1545-1556.

Bastle RM, Maze IS (2019) Chromatin regulation in complex brain disorders. Curr Opin Behav Sci 25:57-65.

Becker JB, McClellan ML, Reed BG (2017) Sex differences, gender and addiction. J Neurosci Res 95:136-147.

Boon R, Silveira GG, Mostoslavsky R (2020) Nuclear metabolism and the regulation of the epigenome. Nat Metab 2:1190-1203.

Bourtchouladze R, Abel T, Berman N, Gordon R, Lapidus K, Kandel ER (1998) Different training procedures recruit either one or two critical periods for contextual memory consolidation, each of which requires protein synthesis and PKA. Learn Mem 5:365-374.

Bridi MS, Hawk JD, Chatterjee S, Safe S, Abel T (2017) Pharmacological activators of the NR4A nuclear receptors enhance LTP in a CREB/CBP-dependent manner. Neuropsychopharmacology 42:1243-1253.

Buenrostro JD, Wu B, Litzenburger UM, Ruff D, Gonzales ML, Snyder MP, Chang HY, Greenleaf WJ (2015) Single-cell chromatin accessibility reveals principles of regulatory variation. Nature 523:486-490.

Burns AM, Gräff J (2020) Cognitive epigenetic priming: leveraging histone acetylation for memory amelioration. Curr Opin Neurobiol 67:75-84.

Cajigas IJ, Tushev G, Will TJ, tom Dieck S, Fuerst N, Schuman EM (2012) The local transcriptome in the synaptic neuropil revealed by deep sequencing and high-resolution imaging. Neuron 74:453-466.

Campbell RR, Wood MA (2019) How the epigenome integrates information and reshapes the synapse. Nat Rev Neurosci 20:133-147.

Chandra J, Miller CP, Singh MM, Rivera-Del Valle N, Manton CA (2011) Therapeutic strategies to enhance the anticancer efficacy of histone deacetylase inhibitors. J Biomed Biotechnol 2011:514261.

Chandra R, Francis TC, Konkalmatt P, Amgalan A, Gancarz AM, Dietz DM, Lobo MK (2015) Opposing role for Egr3 in nucleus accumbens cell subtypes in cocaine action. J Neurosci 35:7927-7937.

Chandra R, Engeln M, Schiefer C, Patton MH, Martin JA, Werner CT, Riggs LM, Francis TC, McGlincy M, Evans B, Nam H, Das S, Girven K, Konkalmatt P, Gancarz AM, Golden SA, Iñiguez SD, Russo SJ, Turecki
G, Mathur BN, et al. (2017a) Drp1 mitochondrial fission in D1 neurons mediates behavioral and cellular plasticity during early cocaine abstinence. Neuron 96:1327-1341.e6.

Chandra R, Engeln M, Francis TC, Konkalmatt P, Patel D, Lobo MK (2017b) A role for peroxisome proliferator-activated receptor gamma coactivator$1 \alpha$ in nucleus accumbens neuron subtypes in cocaine action. Biol Psychiatry 81:564-572.

Cheng A, Wan R, Yang JL, Kamimura N, Son TG, Ouyang X, Luo Y, Okun E, Mattson MP (2012) Involvement of PGC- $1 \alpha$ in the formation and maintenance of neuronal dendritic spines. Nat Commun 3:1250.

Chern Y, Chien T, Fu X, Shah AP, Abel T, Baraban JM (2019) Trax: a versatile signaling protein plays key roles in synaptic plasticity and DNA repair. Neurobiol Learn Mem 159:46-51.

Cole S, Chandra R, Harris M, Patel I, Wang T, Kim H, Jensen L, Russo SJ, Turecki G, Gancarz-Kausch AM, Dietz DM, Lobo MK (2020) Cocaineinduced neuron subtype mitochondrial dynamics through Egr3 transcriptional regulation. bioRxiv. doi: 10.1101/2020.06.27.175349.

Comerford SA, Huang Z, Du X, Wang Y, Cai L, Witkiewicz AK, Walters H, Tantawy MN, Fu A, Manning HC, Horton JD, Hammer RE, McKnight SL, Tu BP (2014) Acetate dependence of tumors. Cell 159:1591-1602.

Conrad KL, Tseng KY, Uejima JL, Reimers JM, Heng LJ, Shaham Y, Marinelli M, Wolf ME (2008) Formation of accumbens GluR2-lacking AMPA receptors mediates incubation of cocaine craving. Nature 454:118-121.

Cryan JF, Dinan TG (2012) Mind-altering microorganisms: the impact of the gut microbiota on brain and behaviour. Nat Rev Neurosci 13:701-712.

Davie JR (2003) Inhibition of histone deacetylase activity by butyrate. J Nutr 133:2485S-2493S.

Day JJ, Roitman MF, Wightman RM, Carelli RM (2007) Associative learning mediates dynamic shifts in dopamine signaling in the nucleus accumbens. Nat Neurosci 10:1020-1028.

Divakaruni SS, Van Dyke AM, Chandra R, LeGates TA, Contreras M, Dharmasri PA, Higgs HN, Lobo MK, Thompson SM, Blanpied TA (2018) Long-term potentiation requires a rapid burst of dendritic mitochondrial fission during induction. Neuron 100:860-875.e7.

Engeln M, Mitra S, Chandra R, Gyawali U, Fox ME, Dietz DM, Lobo MK (2020) Sex-specific role for Egr3 in nucleus accumbens D2-medium spiny neurons following long-term abstinence from cocaine self-administration. Biol Psychiatry 87:992-1000.

Farrelly LA, Thompson RE, Zhao S, Lepack AE, Lyu Y, Bhanu NV, Zhang B, Loh YH, Ramakrishnan A, Vadodaria KC, Heard KJ, Erikson G, Nakadai T, Bastle RM, Lukasak BJ, Zebroski H, Alenina N, Bader M, Berton O, Roeder RG, et al. (2019) Histone serotonylation is a permissive modification that enhances TFIID binding to H3K4me3. Nature 567:535-539.

Feng J, Wilkinson M, Liu X, Purushothaman I, Ferguson D, Vialou V, Maze I, Shao N, Kennedy P, Koo J, Dias C, Laitman B, Stockman V, LaPlant Q, Cahill ME, Nestler EJ, Shen L (2014) Chronic cocaine-regulated epigenomic changes in mouse nucleus accumbens. Genome Biol 15:R65.

Fernandez-Albert J, Lipinski M, Lopez-Cascales MT, Rowley MJ, MartinGonzalez AM, del Blanco B, Corces VG, Barco A (2019) Immediate and deferred epigenomic signatures of in vivo neuronal activation in mouse hippocampus. Nat Neurosci 22:1718-1730.

Fischer A (2014) Epigenetic memory: the Lamarckian brain. EMBO J 33:945-967.

Fischer A, Sananbenesi F, Wang X, Dobbin M, Tsai LH (2007) Recovery of learning and memory is associated with chromatin remodelling. Nature 447:178-182.

Fischer A, Sananbenesi F, Mungenast A, Tsai LH (2010) Targeting the correct HDAC(s) to treat cognitive disorders. Trends Pharmacol Sci 31:605617.

Fu X, Shah A, Baraban JM (2016) Rapid reversal of translational silencing: emerging role of microRNA degradation pathways in neuronal plasticity. Neurobiol Learn Mem 133:225-232.

Gerritsen ME, Williams AJ, Neish AS, Moore S, Shi Y, Collins T (1997) CREB-binding protein/p300 are transcriptional coactivators of p65. Proc Natl Acad Sci USA 94:2927-2932.

Gräff J, Joseph NF, Horn ME, Samiei A, Meng J, Seo J, Rei D, Bero AW, Phan TX, Wagner F, Holson E, Xu J, Sun J, Neve RL, Mach RH, Haggarty SJ, Tsai LH (2014) Epigenetic priming of memory updating during reconsolidation to attenuate remote fear memories. Cell 156:261276. 
Gräff J, Tsai LH (2013) Histone acetylation: molecular mnemonics on the chromatin. Nat Rev Neurosci 14:97-111.

Haettig J, Stefanko DP, Multani ML, Figueroa DX, McQuown SC, Wood MA (2011) HDAC inhibition modulates hippocampus-dependent long-term memory for object location in a CBP-dependent manner. Learn Mem 18:71-79.

Hofford RS, Mervosh NL, Euston TJ, Meckel KR, Orr AT, Kiraly DD (2020) The gut microbiome and its metabolites are necessary for morphine reward. bioRxiv. doi: 10.1101/2020.09.17.302570.

Hu Z, Li Z (2017) miRNAs in synapse development and synaptic plasticity. Curr Opin Neurobiol 45:24-31.

Johnson AR, Thibeault KC, Lopez AJ, Peck EG, Sands LP, Sanders CM, Kutlu MG, Calipari ES (2019) Cues play a critical role in estrous cycle-dependent enhancement of cocaine reinforcement. Neuropsychopharmacology 44:1189-1197.

Josselyn SA, Tonegawa S (2020) Memory engrams: recalling the past and imagining the future. Science 367:eaaw4325.

Kau KS, Madayag A, Mantsch JR, Grier MD, Abdulhameed O, Baker DA (2008) Blunted cystine-glutamate antiporter function in the nucleus accumbens promotes cocaine-induced drug seeking. Neuroscience 155:530-537.

Kiraly DD, Walker DM, Calipari ES, Labonte B, Issler O, Pena CJ, Ribeiro EA, Russo SJ, Nestler EJ (2016) Alterations of the host microbiome affect behavioral responses to cocaine. Sci Rep 6:35455.

Koob GF, Volkow ND (2016) Neurobiology of addiction: a neurocircuitry analysis. Lancet Psychiatry 3:760-773.

Korzus E, Rosenfeld MG, Mayford M (2004) CBP histone acetyltransferase activity is a critical component of memory consolidation. Neuron 42:961-972.

Kourrich S, Rothwell PE, Klug JR, Thomas MJ (2007) Cocaine experience controls bidirectional synaptic plasticity in the nucleus accumbens. J Neurosci 27:7921-7928.

Kutlu MG, Zachry JE, Brady LJ, Melugin PR, Kelly SJ, Sanders C, Tat J, Johnson AR, Thibeault K, Lopez AJ, Siciliano CA, Calipari ES (2020) A novel multidimensional reinforcement task in mice elucidates sex-specific behavioral strategies. Neuropsychopharmacology 45:1463-1472.

Lepack AE, Werner CT, Stewart AF, Fulton SL, Zhong P, Farrelly LA, Smith AC, Ramakrishnan A, Lyu Y, Bastle RM, Martin JA, Mitra S, O'Connor RM, Wang ZJ, Molina H, Turecki G, Shen L, Yan Z, Calipari ES, Dietz DM, et al. (2020) Dopaminylation of histone H3 in ventral tegmental area regulates cocaine seeking. Science 368:197-201.

Levenson JM, Sweatt JD (2005) Epigenetic mechanisms in memory formation. Nat Rev Neurosci 6:108-118.

Levenson JM, Sweatt JD (2006) Memory. Cell Mol Life Sci 63:1009-1016.

Levenson JM, O’Riordan KJ, Brown KD, Trinh MA, Molfese DL, Sweatt JD (2004) Regulation of histone acetylation during memory formation in the hippocampus. J Biol Chem 279:40545-40559.

Li X, Gianoulis TA, Yip KY, Gerstein M, Snyder M (2010) Extensive in vivo metabolite-protein interactions revealed by large-scale systematic analyses. Cell 143:639-650.

Li Z, Okamoto KI, Hayashi Y, Sheng M (2004) The importance of dendritic mitochondria in the morphogenesis and plasticity of spines and synapses. Cell 119:873-887.

Lobo MK, Nestler EJ (2011) The striatal balancing act in drug addiction: distinct roles of direct and indirect pathway medium spiny neurons. Front Neuroanat 5:41.

Madabhushi R, Gao F, Pfenning AR, Pan L, Yamakawa S, Seo J, Rueda R, Phan TX, Yamakawa H, Pao PC, Stott RT, Gjoneska E, Nott A, Cho S, Kellis M, Tsai LH (2015) Activity-induced DNA breaks govern the expression of neuronal early-response genes. Cell 161:1592-1605.

Madugalle SU, Meyer K, Wang DO, Bredy TW (2020) RNA N6-methyladenosine and the regulation of RNA localization and function in the brain. Trends Neurosci 43:1011-1023.

Mao JH, Kim YM, Zhou YX, Hu D, Zhong C, Chang H, Brislawn CJ, Fansler S, Langley S, Wang Y, Peisl BY, Celniker SE, Threadgill DW, Wilmes P, Orr G, Metz TO, Jansson JK, Snijders AM (2020) Genetic and metabolic links between the murine microbiome and memory. Microbiome 8:53.

Marco A, Meharena HS, Dileep V, Raju RM, Davila-Velderrain J, Zhang AL, Adaikkan C, Young JZ, Gao F, Kellis M, Tsai LH (2020) Mapping the epigenomic and transcriptomic interplay during memory formation and recall in the hippocampal engram ensemble. Nat Neurosci 23:1606-1617.
Martin KC, Barad M, Kandel ER (2000) Local protein synthesis and its role in synapse-specific plasticity. Curr Opin Neurobiol 10:587-592.

Maze I, Chaudhury D, Dietz DM, Von Schimmelmann M, Kennedy PJ, Lobo MK, Sillivan SE, Miller ML, Bagot RC, Sun H, Turecki G, Neve RL, Hurd YL, Shen L, Han MH, Schaefer A, Nestler EJ (2014) G9a influences neuronal subtype specification in striatum. Nat Neurosci 17:533-539.

Mercer TR, Mattick JS (2013) Structure and function of long noncoding RNAs in epigenetic regulation. Nat Struct Mol Biol 20:300-307.

Mercer TR, Dinger ME, Sunkin SM, Mehler MF, Mattick JS (2008) Specific expression of long noncoding RNAs in the mouse brain. Proc Natl Acad Sci USA 105:716-721.

Mews P, Calipari ES (2017) Cross-talk between the epigenome and neural circuits in drug addiction. Prog Brain Res 235:19-63.

Mews P, Donahue G, Drake AM, Luczak V, Abel T, Berger SL (2017) AcetylCoA synthetase regulates histone acetylation and hippocampal memory. Nature 546:381-386.

Mews P, Walker DM, Nestler EJ (2018) Epigenetic priming in drug addiction. Cold Spring Harb Symp Quant Biol 83:131-139.

Mews P, Egervari G, Nativio R, Sidoli S, Donahue G, Lombroso SI, Alexander DC, Riesche SL, Heller EA, Nestler EJ, Garcia BA, Berger SL (2019) Alcohol metabolism contributes to brain histone acetylation. Nature 574:717-721.

Moffett JR, Puthillathu N, Vengilote R, Jaworski DM, Namboodiri AM (2020) Acetate revisited: a key biomolecule at the nexus of metabolism, epigenetics, and oncogenesis: 2. Acetate and ACSS2 in health and disease. Front Physiol 11:580171.

Nestler EJ, Lüscher C (2019) The molecular basis of drug addiction: linking epigenetic to synaptic and circuit mechanisms. Neuron 102:48-59.

Nestler EJ, Barrot M, Self DW (2001) FosB: a sustained molecular switch for addiction. Proc Natl Acad Sci USA 98:11042-11046.

Oliveira AM, Estevez MA, Hawk JD, Grimes S, Brindle PK, Abel T (2011) Subregion-specific p300 conditional knock-out mice exhibit long-term memory impairments. Learn Mem 18:161-169.

Pardo M, Betz AJ, San Miguel N, López-Cruz L, Salamone JD, Correa M (2013) Acetate as an active metabolite of ethanol: studies of locomotion, loss of righting reflex, and anxiety in rodents. Front Behav Neurosci 7:81.

Park AJ, Havekes R, Fu X, Hansen R, Tudor JC, Peixoto L, Li Z, Wu YC, Poplawski SG, Baraban JM, Abel T (2017) Learning induces the translin/ trax RNase complex to express activin receptors for persistent memory. Elife 6:e27872.

Peixoto L, Abel T (2013) The role of histone acetylation in memory formation and cognitive impairments. Neuropsychopharmacology 38:62-76.

Peleg S, Sananbenesi F, Zovoilis A, Burkhardt S, Bahari-Javan S, Agis-Balboa RC, Cota P, Wittnam JL, Gogol-Doering A, Opitz L, Salinas-Riester G, Dettenhofer M, Kang H, Farinelli L, Chen W, Fischer A (2010) Altered histone acetylation is associated with age-dependent memory impairment in mice. Science 328:753-756.

Pierce RC, Bell K, Duffy P, Kalivas PW (1996) Repeated cocaine augments excitatory amino acid transmission in the nucleus accumbens only in rats having developed behavioral sensitization. J Neurosci 16:1550-1560.

Pietrocola F, Galluzzi L, Bravo-San Pedro JM, Madeo F, Kroemer G (2015) Acetyl coenzyme A: a central metabolite and second messenger. Cell Metab 21:805-821.

Poo M, Pignatelli M, Ryan TJ, Tonegawa S, Bonhoeffer T, Martin KC, Rudenko A, Tsai LH, Tsien RW, Fishell G, Mullins C, Gonçalves JT, Shtrahman M, Johnston ST, Gage FH, Dan Y, Long J, Buzsáki G, Stevens C (2016) What is memory? The present state of the engram. BMC Biol 14:40.

Raveendra BL, Swarnkar S, Avchalumov Y, Liu XA, Grinman E, Badal K, Reich A, Pascal BD, Puthanveettil SV (2018) Long noncoding RNA GM12371 acts as a transcriptional regulator of synapse function. Proc Natl Acad Sci USA 115:E10197-E10205.

Reid MS, Berger SP (1996) Evidence for sensitization of cocaine-induced nucleus accumbens glutamate release. Neuroreport 7:1325-1329.

Rivera CM, Ren B (2013) Mapping human epigenomes. Cell 155:39-55.

Robison AJ, Nestler EJ (2011) Transcriptional and epigenetic mechanisms of addiction. Nat Rev Neurosci 12:623-637.

Rotem A, Ram O, Shoresh N, Sperling RA, Goren A, Weitz DA, Bernstein BE (2015) Single-cell ChIP-seq reveals cell subpopulations defined by chromatin state. Nat Biotechnol 33:1165-1172. 
Sarkola T, Iles MR, Kohlenberg-Mueller K, Eriksson CJ (2002) Ethanol, acetaldehyde, acetate, and lactate levels after alcohol intake in white men and women: effect of 4-methylpyrazole. Alcoholism Clin Exp Res 26:239-245.

Savell KE, Bach SV, Zipperly ME, Revanna JS, Goska NA, Tuscher JJ, Duke CG, Sultan FA, Burke JN, Williams D, Ianov L, Day JJ (2019) A neuronoptimized CRISPR/dCas9 activation system for robust and specific gene regulation. eNeuro 6:ENEURO.0495-18.2019.

Savell KE, Tuscher JJ, Zipperly ME, Duke CG, Phillips RA, Bauman AJ, Thukral S, Sultan FA, Goska NA, Ianov L, Day JJ (2020) A dopamineinduced gene expression signature regulates neuronal function and cocaine response. Sci Adv 6:eaba4221.

Schmitt M, Matthies H (1979) Biochemical studies on histones of the central nervous system: III. Incorporation of $\left[{ }^{14} \mathrm{C}\right]$-acetate into the histones of different rat brain regions during a learning experiment. Acta Biol Med Ger 38:683-689.

Shah P, Nankova BB, Parab S, La Gamma EF (2006) Short chain fatty acids induce $\mathrm{TH}$ gene expression via ERK-dependent phosphorylation of CREB protein. Brain Res 1107:13-23.

Shahbazian MD, Grunstein M (2007) Functions of site-specific histone acetylation and deacetylation. Annu Rev Biochem 76:75-100.

Sharma U, Rando OJ (2017) Metabolic inputs into the epigenome. Cell Metab 25:544-558.

Soliman ML, Rosenberger TA (2011) Acetate supplementation increases brain histone acetylation and inhibits histone deacetylase activity and expression. Mol Cell Biochem 352:173-180.

Stefanko DP, Barrett RM, Ly AR, Reolon GK, Wood MA (2009) Modulation of long-term memory for object recognition via HDAC inhibition. Proc Natl Acad Sci USA 106:9447-9452.

Surmeier DJ, Ding J, Day M, Wang Z, Shen W (2007) D1 and D2 dopaminereceptor modulation of striatal glutamatergic signaling in striatal medium spiny neurons. Trends Neurosci 30:228-235.

Sutton MA, Schuman EM (2006) Dendritic protein synthesis, synaptic plasticity, and memory. Cell 127:49-58.

Vecsey CG, Hawk JD, Lattal KM, Stein JM, Fabian SA, Attner MA, Cabrera SM, McDonough CB, Brindle PK, Abel T, Wood MA (2007) Histone deacetylase inhibitors enhance memory and synaptic plasticity via CREB: CBP-dependent transcriptional activation. J Neurosci 27:6128-6140.
Volkow ND, Morales M (2015) The brain on drugs: from reward to addiction. Cell 162:712-725.

Waddington CH (1942) The epigenotype. Endeavour 4:18-20.

Walker DM, Cates HM, Loh YH, Purushothaman I, Ramakrishnan A, Cahill KM, Lardner CK, Godino A, Kronman HG, Rabkin J, Lorsch ZS, Mews P, Doyle MA, Feng J, Labonté B, Koo JW, Bagot RC, Logan RW, Seney ML, Calipari ES, et al. (2018) Cocaine self-administration alters transcriptome-wide responses in the brain's reward circuitry. Biol Psychiatry 84:867-880.

Walker DM, Cates HM, Heller EA, Nestler EJ (2015) Regulation of chromatin states by drugs of abuse. Curr Opin Neurobiol 30:112-121.

Wellen KE, Hatzivassiliou G, Sachdeva UM, Bui TV, Cross JR, Thompson CB (2009) ATP-citrate lyase links cellular metabolism to histone acetylation. Science 324:1076-1080.

Wood MA, Kaplan MP, Park A, Blanchard EJ, Oliveira AM, Lombardi TL, Abel T (2005) Transgenic mice expressing a truncated form of CREBbinding protein (CBP) exhibit deficits in hippocampal synaptic plasticity and memory storage. Learn Mem 12:111-119.

Wood MA, Hawk JD, Abel T (2006a) Combinatorial chromatin modifications and memory storage: a code for memory? Learn Mem 13:241-244.

Wood MA, Attner MA, Oliveira AM, Brindle PK, Abel T (2006b) A transcription factor-binding domain of the coactivator CBP is essential for long-term memory and the expression of specific target genes. Learn Mem 13:609-617.

Xu SJ, Heller EA (2019) Recent advances in neuroepigenetic editing. Curr Opin Neurobiol 59:26-33.

Yim YY, Teague CD, Nestler EJ (2020) In vivo locus-specific editing of the neuroepigenome. Nat Rev Neurosci 21:471-484.

Zachry JE, Johnson AR, Calipari ES (2019) Sex differences in value-based decision making underlie substance use disorders in females. Alcohol Alcohol 54:339-341.

Zaware N, Zhou MM (2019) Bromodomain biology and drug discovery. Nat Struct Mol Biol 26:870-879.

Zovkic IB (2020) Epigenetics and memory: an expanded role for chromatin dynamics. Curr Opin Neurobiol 67:58-65.

Zovkic IB, Paulukaitis BS, Day JJ, Etikala DM, Sweatt JD (2014) Histone H2A.Z subunit exchange controls consolidation of recent and remote memory. Nature 515:582-586. 